\title{
Laser markability of PVC coated automotive electric cables
}

\author{
E. Bitay ${ }^{*}$
}

Sapientia Hungarian University of Transylvania, Faculty of Technical and Human Sciences, 540485 Târgu-Mureş, Op. 9., Cp. 4., Romania

Received 26 June 2018; accepted in revised form 29 November 2018

\begin{abstract}
This article describes the test results for laser markability of automotive electrical cables. The insulation is PVC, but the colour and construction of the insulations are different. Two types of laser workstations were used, one with a wavelength of $1064 \mathrm{~nm}$ and another with $532 \mathrm{~nm}$. The penetration depth of the laser beam was determined by optical microscopy on cross sections. The $1064 \mathrm{~nm}$ laser beam can mark all investigated materials with good contrast, except the yellow insulation. The $532 \mathrm{~nm}$ laser beam with fast speed can hardly produce contrast with any of the materials. The laser markability of the yellow insulation was found to be the most problematic. On the two-layer insulation, despite the whitening of the inner material, dark marking is produced because the heat developing on the interface of the two layers will heat up and carbonize the transparent layer.
\end{abstract}

Keywords: materials testing, industrial application, laser markability, PVC coated cable

\section{Introduction}

Laser marking of plastics is the most widespread laser surface modification procedure. Marking is part of mass production, and the speed of the product often cannot be followed with the naked eye, and also, sometimes all the products have to be marked with an individual marker.

Polymers can be marked with a laser with one of the following mechanisms: ablation, bleaching (thermal bleaching) [1], carbonisation [2], colour change (colour-formation, colouring, colour marking [3,4]), darkening/whitening [5, 6], dehydration [7], doping $[8,9]$, engraving $[10]$, foaming $[8,11-13]$, melting, optical breakdown [14], oxidation/reduction on metallized surfaces [15], transfer and unzipping [16, 17]. Laser beam can make pits and rims [18], craters [19], but there are papers in which the same interaction between laser beam and material is called once ablation [20], sometimes etching [21]. Laser ablation is a current application for thin layer machining [22-29], but is not applied for marking of electric cables.
Laser surface treatment can serve purposes other than marking, such as increasing the wettability [30, 31], surface texturing [32], structuration [33-35], patterning [36], hydrofobization [37-39] or stereo-lithography $[40,41]$. Automotive and aerospace cables can only be laser marked by thermal bleaching since all other marking methods would change the structure or amount of the material to such an extent that it would compromise the basic function of the cable.

Markings must satisfy certain technological criteria, such as visibility, legibility, durability or laser markability [42-45], but marking speed (cycle time) is also a basic criterion in industrial applications.

During laser marking of thermoplastics, various interactions take place in the polymer, some of which are hardly known as the pulse time of the laser can be measured in $\mu \mathrm{s}$, ns, ps or fs [46-51], but the temperature during marking can reach up to $800^{\circ} \mathrm{C}$ [8]. Thermoplastics without fillers or pigments can be divided into three main groups according to their suitability for laser marking: 
- Members of group 1 absorb laser rays well, therefore they are carbonized and the marking will be dark. Such materials are polyesters (PES) and polysulfones (PSU).

- In the materials of group 2, absorption and carbonization are irregular. This group includes polystyrenes (PS), some foamable copolymers, such as ABS (acrylonitrile-butadiene-styrene), and PET (polyethylene terephthalate) and PBT (polybutylene terephthalate). With the addition of the proper pigment or additive, these polymers can also be made well markable.

- Group 3 includes polymers, such as POM (polyoxymethylene), PP (polypropylene), PE (polyethylene) and PPS (polyphenylene sulfide), which cannot be marked with laser in their original uncoloured state; the laser does not cause a change in colour or reflection. For laser marking of polyurethane with a Nd:YAG laser (YAG means yttrium-aluminium-garnet), bismuth oxide was applied successfully [52].

The basic criterion for laser markability is that the material should absorb the energy of the laser. The polymer can absorb laser radiation itself but if it does not, colorants (pigments) or other additives need to be added $[53,54]$. Therefore, additives play a very important role in laser marking; they can make the marking process quasi-independent of the polymer [55, 56]. The first additives to improve the laser markability were mica-based pigments. Carbon black and rutile were first used for this purpose in 1994. Besides $\mathrm{TiO}_{2}$, that is used in thermoplastic elastomers [5], other white pigments such as $\mathrm{Ba}_{2} \mathrm{SO}_{4}, \mathrm{Al}_{2} \mathrm{O}_{3}$, and $\mathrm{ZnO}$ are also used [16]. One of the newest additives to improve the laser markability of PA (polyamide) is antimony-trioxide [57], combined with $\mathrm{Ti}, \mathrm{Fe}, \mathrm{Cr}$, Ni oxide, and 10-50 nm, organic pigments (copper phthalocyanines, dioxazines, anthraquinones, diketopyrrolopyrrole) to make laser transparent polymers (ABS, PC (polycarbonate)) markable [58].

Additives that improve laser markability can be dispersed or aggregated in the material or in a coating. In multi-layered coating, there is a first pigment (rutile or anatase, antimony trioxide, PEEK (polyetheretherketone), PES) markable with ultraviolet laser, and a second pigment (silica, magnesia alumina or diamond), which does not absorb ultra-violet (UV) radiation and looks white [59].

There are practical criteria of choosing the appropriate laser, but the most important characteristic is wavelength. There are lasers from UV to the far infrared, and they can be continuous or high-peak power, short-duration pulsed laser beams [11]. The most common lasers for automotive cable marking include the following:

- $\mathrm{CO}_{2}$ gas laser with $10640 \mathrm{~nm}$ wavelength (far-infrared); it is used also for thermosetting polymers [60],

- Xenon chloride $(\mathrm{XeCl})$ excimer gas laser with a wavelength of $308 \mathrm{~nm}$ (UV),

- Nd:YAG solid-state laser with a wavelength of $1064 \mathrm{~nm}$ (near-infrared),

- Ytterbium fibre laser with a wavelength of $1060 \mathrm{~nm}$ (near-infrared),

- Frequency-doubled Nd:YVO, 532 nm wavelength (visible, green),

- Frequency-tripled Nd:YVO 4 or Nd:YAG solidstate laser with a wavelength of $355 \mathrm{~nm}$ (UV).

UV lasers have been spreading fast recently. The reason for this is that the absorption coefficient of polymers can increase up to 20 times higher if the wavelength of the laser decreases from 1064 to $355 \mathrm{~nm}$. In the case of the hard PVC (poly(vinyl chloride)), the increase is 'only' five times (from 0.06 to $0.301 / \mathrm{mm}$ ) [16]. However, the newest trend in the laser marking of polymer materials shows the substitution of UV lasers by ps green lasers (532 $\mathrm{nm}$ ), because of the increased process speed, the sufficient contrast, and the reduced cost (less maintenance and higher lifetime).

This paper focuses on the investigation of the laser markability of cables of various colours, and one of the important issues was how much the cycle time of laser marking can be reduced in special 'marking on the fly' process.

\section{Materials and equipment}

We examined thermoplastic automotive electric cables with PVC insulation, but the diameter of the cables, and the colour and structural layout of the insulation were different. The insulations were lasermarked with an experimental program of four series, on TRUMPF VectorMarc VMc5 and VMc4 workstations, by using the 'marking on the fly' process. The main technological variables (not all details) can be found in Table 1.

After the experiments, the samples were first examined with the naked eye, and then some representative samples were examined with a microscope to determine the penetration depth of the laser, which 
causes meso-scale structural transformations in the zone under the surface of the insulation.

Cables with the following insulation colours were examined: yellow, red, red + black, green + yellow, black and dark brown. The identification of the insulation's polymer and its additives (e.g. plasticizers, pigments) was not a part of this work, but differential scanning calorimetry (DSC) - using a Perkin-Elmer Pyris type calorimeter - and energy dispersive spectrometry (EDS) were carried out for the identification of the polymer and the inorganic additives.

The plasticizers mainly used in PVC are phthalates, e.g. dibutyl phthalate (DBP), dioctyl phthalate (DOP) [61], diisodecyl phthalate (DIDP) and di(2-ethylhexyl) phthalate (DEHP) [62, 63]. There are also many bio-based plasticizers [64-67], in which the soybean oil and the epoxidizes soybean oil (ESBO) and the acetic acid ester (AAE) are the most common $[68,69]$. Cardanol is a natural resource with low cost and low toxicity [70]. Cardanol is also used as a perfect raw material for the high grade insulating coatings [71, 72], and this is valid for the cardanol acetate (CA) [73], the epoxidized cardanol acetate (ECA) [74] and the cardanol derivatives as well [63].

A Nikon SMZ-2 type stereo-microscope, Jeol JSM6380 and Zeiss EVO 10 type scanning electron microscopes and Olympus PMG-3 metallurgical microscope were used for the examination of the cable surfaces and the cross-sectional cut samples. The penetration depth of the laser beam was determined in the microstructural images with the ImagePro-Plus image analyser software.

\section{Results and discussion}

\subsection{Analysis of the insulation and the burning residue}

Figure 1a shows the DSC heat flow curves of two cable insulations; this measurement denotes that the materials of the insulations are a generally used, medium plasticizer containing PVC. A detail of the surface of the red insulation is seen in Figure 1b, and the burning residue in Figure 1c respectively. The small white particles in Figure $1 \mathrm{~b}$ were analysed as particularly $\mathrm{Ca}$ as well as low quantity of $\mathrm{Zn}, \mathrm{Mg}$, $\mathrm{Al}$, Ti and Fe compounds. These are also the constituents of the burning residue as the EDS analysis determined. The performed EDS analyses prove that the inorganic additives are particularly $\mathrm{Ca}$ as well as low quantity of $\mathrm{Zn}, \mathrm{Mg}$, $\mathrm{Al}$, Ti and Fe compounds;
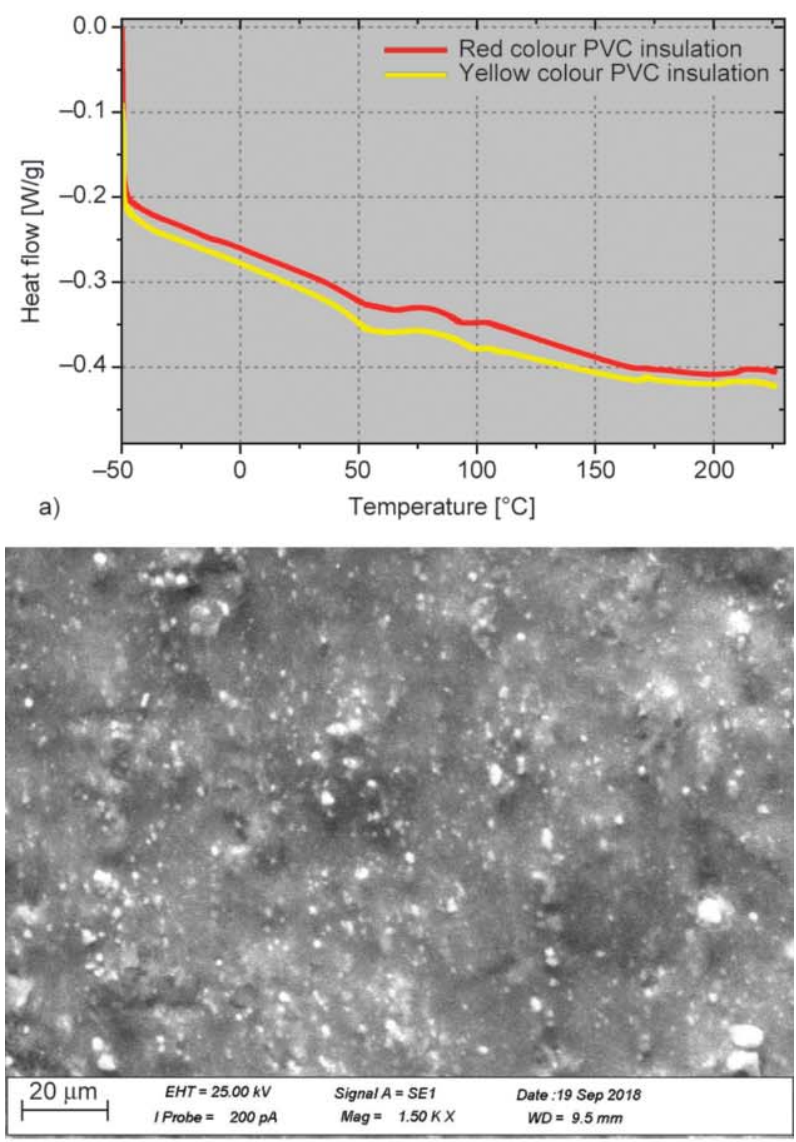

b)

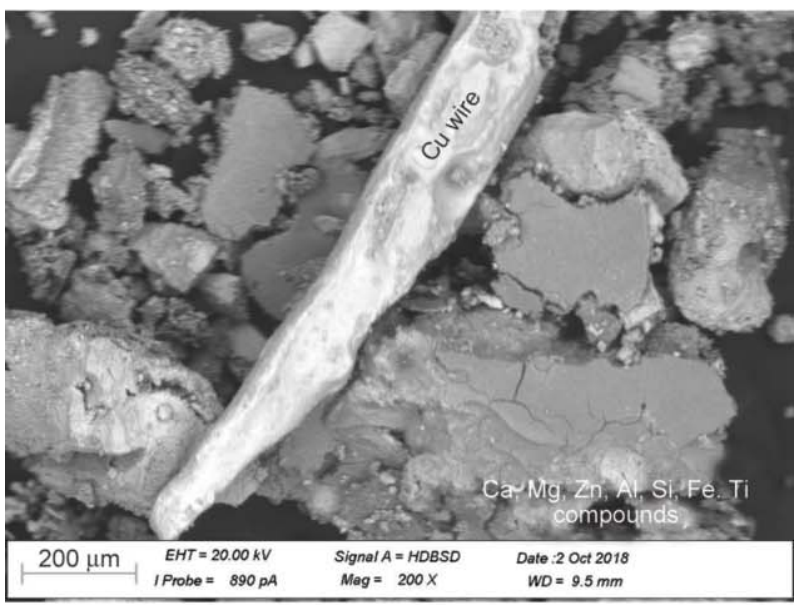

c)

Figure 1. a) DCS heat flow curves of two (red and yellow) PVC insulations. b) The surface of the red colour PVC insulation. c) The residue of the red cable after burning.

this analysis cannot determine the nature of organic pigments and plasticizers.

\subsection{Visual examinations and evaluation}

Since this investigation was connected to the manufacturing development program of a car manufacturer, first, with the visual inspection, the most important 

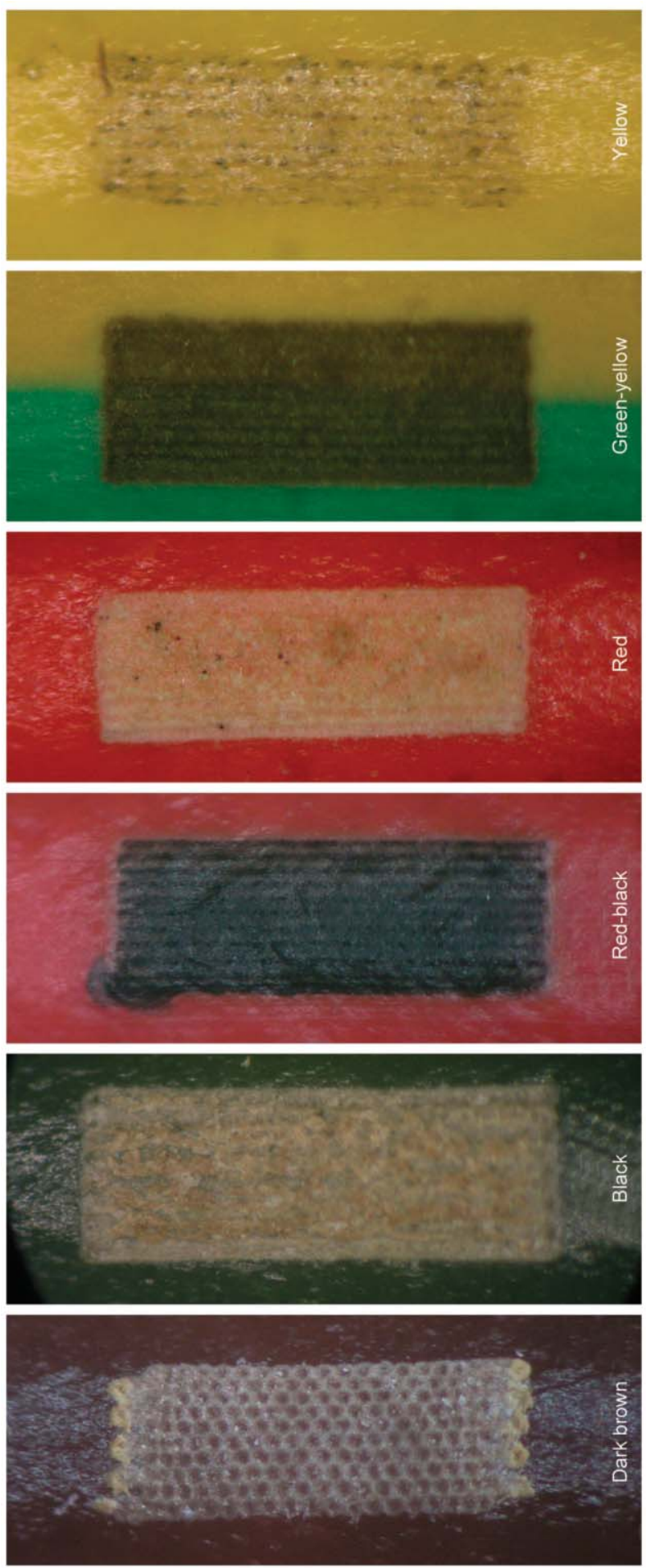

Figure 2. The $2.0 \times 0.6 \mathrm{~mm}$ laser markings on the insulation of cables of various colours.

visibility characteristics had to be determined: colour of marking, contrast, homogeneity, and scratch resistance. Scratch resistance also has to be evaluated visually, after a special rubbing test (but this article does not discuss this in detail).

Figure 2 shows the representative, selected markings whose microscopic test characteristics this article presents.

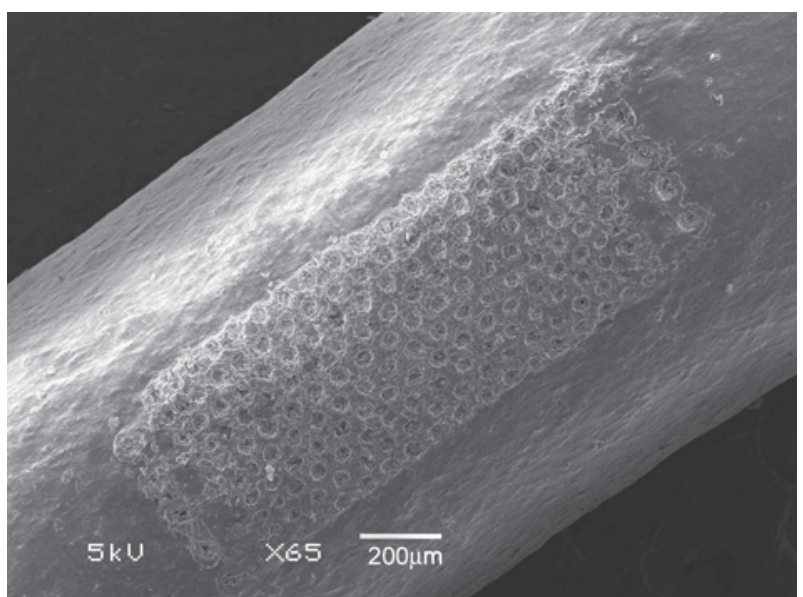

a)

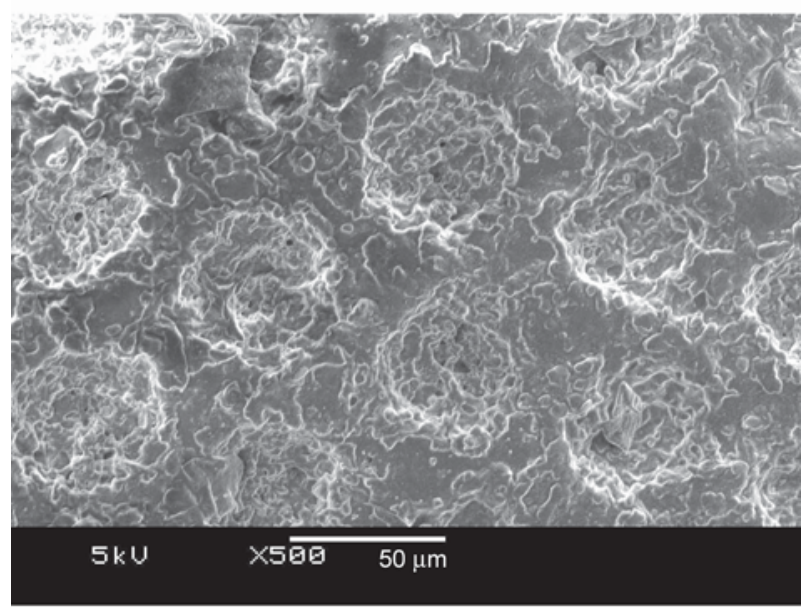

b)

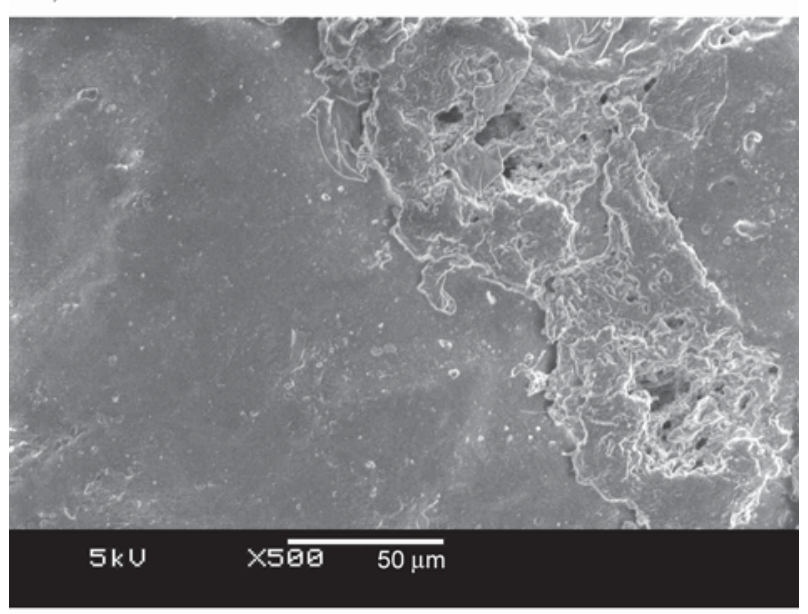

c)

Figure 3. Laser marking (a) and its certain details on the dark brown insulation, in the middle of the marking (b) and at the edge of the marking (c).

Laser marking formed a special surface texture on the dark brown insulation. The scanning electron microscopic examination of the texture (Figure 3) showed that the 30 micron diameter laser pulse series produced individual craters in the surface, positioned like a raster. 
Table 1. The area of marking is $2.0 \times 0.6 \mathrm{~mm}$ on the insulation of each cable.

\begin{tabular}{|c|c|c|c|c|}
\hline & Series 1 & Series 2 & Series 3 & Series 4 \\
\hline Laser type & VMc5 & VMc5 & VMc5 & VMc4 \\
\hline Power & 95 & 95 & 95 & 95 \\
\hline Wavelength & 1064 & 1064 & 1064 & 532 \\
\hline Optical focus & 163 & 163 & 163 & 160 \\
\hline Spot size & 40 & 40 & 40 & 20 \\
\hline Filling distance $[\mu \mathrm{m}]$ & 50 & 50 & 50 & 50 \\
\hline Frequency & 65 & 55 & 55 & 20 \\
\hline$[\mathrm{mm} / \mathrm{s}]$ & 5000 & 500 & 500 & 500 \\
\hline Pulse width & 5 & 5 & 5 & 5 \\
\hline Marking time & 0.12 & 0.26 & 0.60 & 0.23 \\
\hline
\end{tabular}

The inner part of the craters and the zones between them were melted for a short time, then quickly cooled and solidified. In addition to the variables given in Table 1, surface morphology is also strongly affected by the defocus and the number of pulses per point. The optimum of these is usually sensitive and protected data.

Table 2 contains the general evaluation of the visibility of laser markings during visual inspection; these evaluations are built into the manufacturing process as grading categories. In the whole DOE (design of experiment) the following can be said about the suitability of the two kinds of laser marking systems (VMc4 and VMc5), taking into account that there are two technological variables provided, one with fast speed $(5000 \mathrm{~m} / \mathrm{s})$ and the other one with slow speed $(500 \mathrm{~m} / \mathrm{s})$.

- The VMc5 system with slow speed can mark all the different materials with good contrast, except the yellow insulation.

- The VMc5 system with fast speed can only mark black, brown and green/yellow insulations with good contrast.

- The VMc4 system with slow speed can mark with good contrast all the materials, except yellow, but with fast speed it can hardly produce contrast with any of the materials.

Table 2. Evaluation of laser markings on the base of visual and functional requirements.

\begin{tabular}{|l|l|l|l|l|}
\hline & Series 1 & Series 2 & Series 3 & Series 4 \\
\hline Colour of marking & Dark & Dark/Clear & Dark & Dark \\
\hline Contrast & Middle & High & High & High \\
\hline Homogeneity & High & High & High & High \\
\hline Scratch resistance & Yes & Yes & Yes & No \\
\hline
\end{tabular}

\subsection{Microscopic examination of the penetration depth of laser marking}

Cross-sectional samples of the cables were embedded in Duracryl resin, and then wet grinded on $\mathrm{SiC}$ grinding papers of gradually finer grades. Figure $4 \mathrm{a}$ shows the effect of laser marking on the cross-section of the yellow insulation: the $532 \mathrm{~nm}$ laser penetrates relatively deep through narrow channels, but the visibility of the marking is weak; this is clearly visible in Figure 2. Figure 4a also depicts the method of determining penetration depth: penetration depth is the distance between the two outer dashed lines, as the arrows show. The penetration depth of the $1064 \mathrm{~nm}$ laser is considerably smaller in both the yellow and the green insulators, as can be seen in Figure $4 b$, but this is good because laser energy is ab-

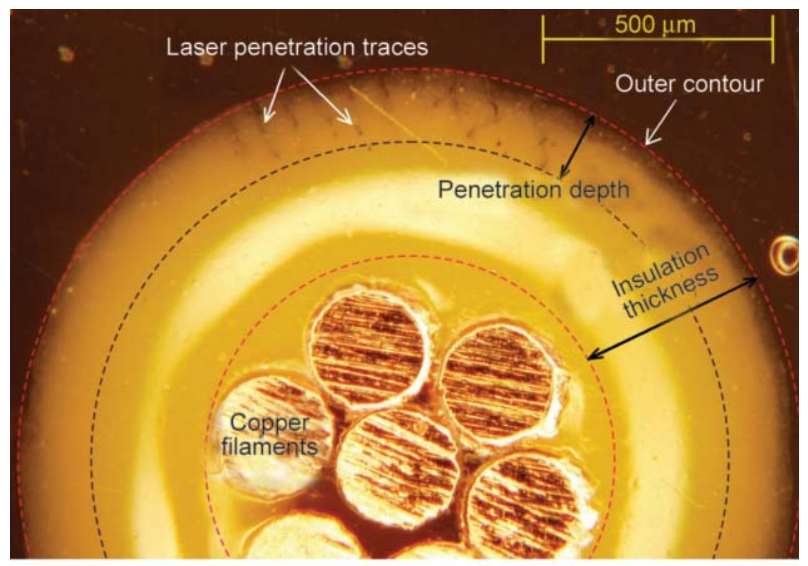

a)

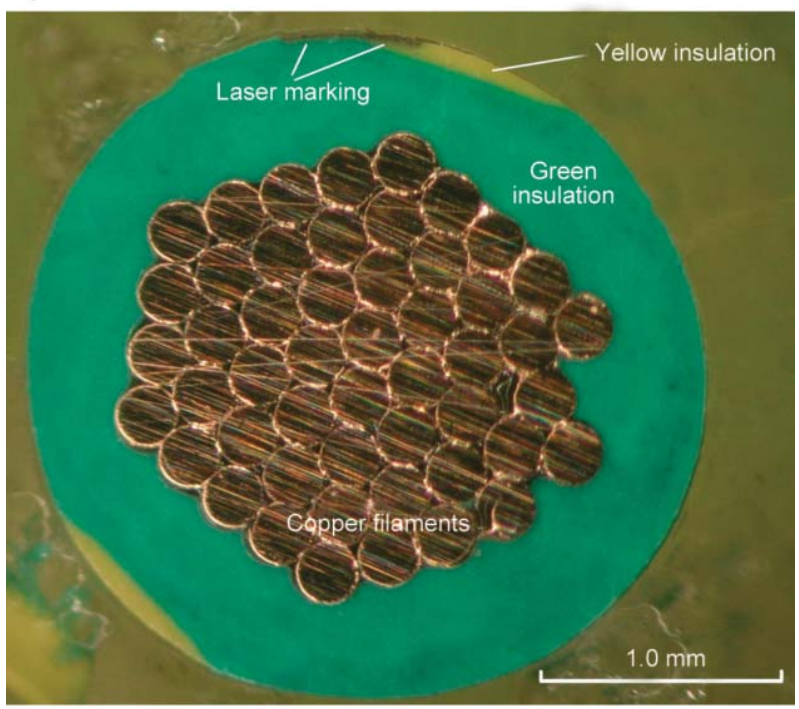

b)

Figure 4. Cross-sectional images of two cables showing the penetration of the laser beam; a) Penetration of the $532 \mathrm{~nm}$ laser beam into the yellow insulation; the arrows show the determination of the penetration depth. b) Penetration of the $1064 \mathrm{~nm}$ laser beam into the green-yellow insulation. 
sorbed in the material's surface zone and a clearly visible black (dark) mark is produced.

In the red insulations, the $1064 \mathrm{~nm}$ laser is absorbed relatively deeply (Figure 5a), and marking takes the

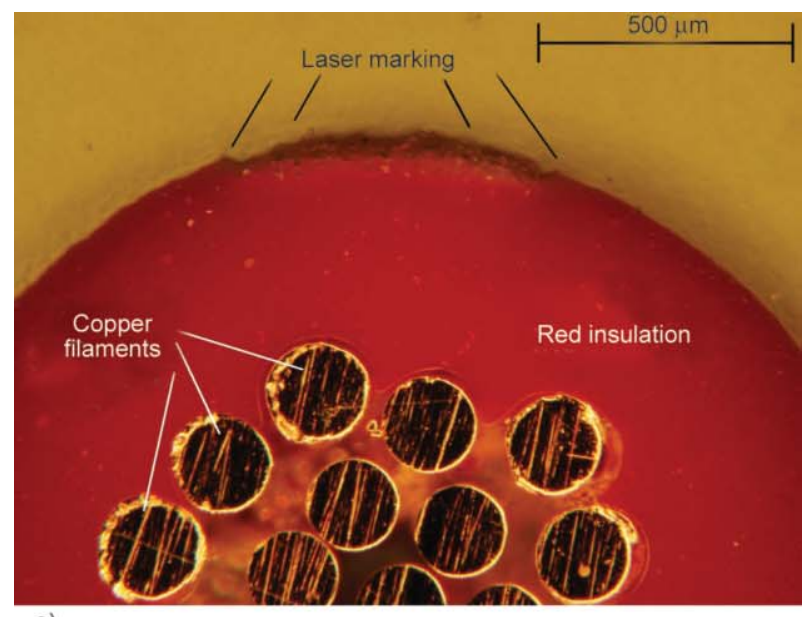

a)

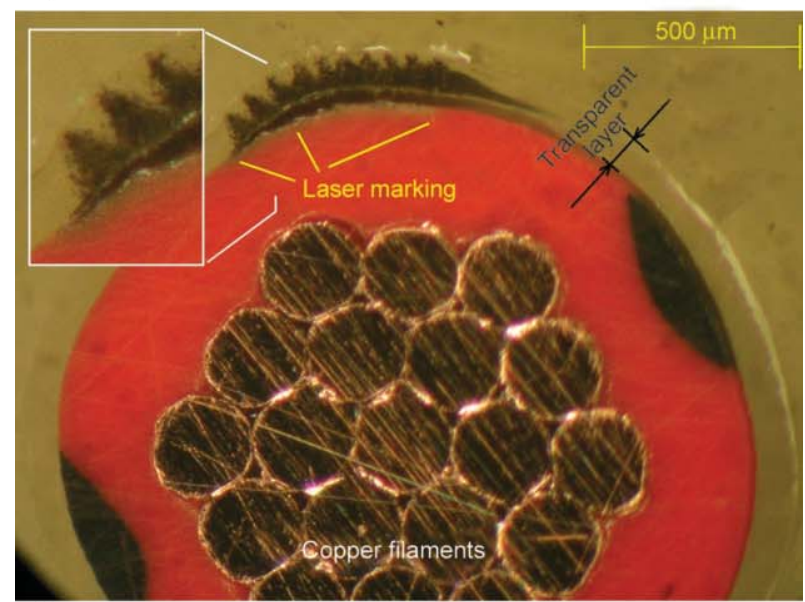

b)

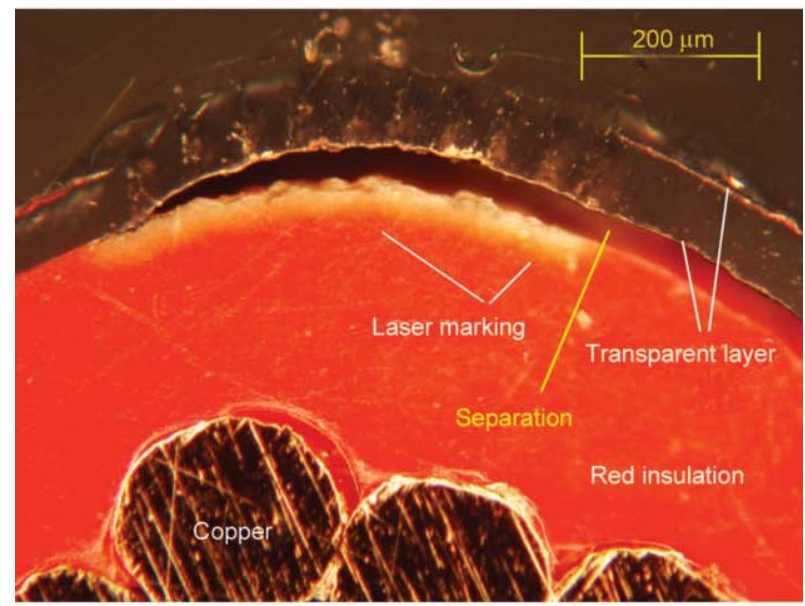

c)

Figure 5. The cross-sectional images of the cables with red insulation; a) the cross section of white marking on the simple red insulation, b) the cross section of black marking on the red ACW, c) the separation of the whitened red layer and the transparent fluoropolymer layer above it. form of whitening. This whitening is the result of the thermally induced change of the colorant. However, Figure 2 shows that a black mark formed on the red surface of the red-black insulation. How is this possible? There can be such situations in which the colours can be the results of the electron transfer from photo-effected reaction; e.g. the PVA (poly(vinyl alcohol)) supplies the electrons to the self-bleached processes [75], but the examined situation is much simpler and clearer.

Figure $5 \mathrm{~b}$ clearly shows that on the given cable, the red insulation (which contains two black stripes) is covered by an outer, completely transparent layer of about 50 microns thickness. This is a so-called automotive composite wire (ACW), with a radiation crosslinked fluoropolymer outer insulation protecting the PVC inner insulation; therefore the cable withstands thermal and mechanical loads in the engine bay. Transparency also holds for the $1064 \mathrm{~nm}$ laser, at least the images inside Figure $5 \mathrm{~b}$ and $5 \mathrm{c}$ show that the outer surface of the transparent layer was not damaged by the laser beam. Figure $5 \mathrm{c}$ also shows that the material of the red insulation was whitened by the laser.

The marking, however, still became black since the heat generated on the outer surface of the red insulation heated the transparent layer. This heating affected less and less volume as it moved outwards, this is why the cross section of the zones heated with the laser looks like triangles pointing outwards. The transparent layer can similarly heated and plasticized by means of heat conduction [48], but at the boundary of the red and the transparent layer so much heat was generated that gas was produced due to thermal decomposition, and its pressure separated the two layers; a similar explanation is described by Zelenska et al. [76].

The cross section of the black cable is shown in Figure 6. This cable had the smallest diameter $(1.6 \mathrm{~mm})$, therefore there is a greater difference between the angles the laser hits the edge and the centre of the marked area. In spite of the greater surface curvature change, the laser had relatively uniform penetration and penetration depth was small.

The microscopic examination of the black and dark brown insulation with the Olympus PMG-3 inverted microscope required special imaging modes. The cross-sectional examination of the dark brown insulation in Figure 7a required dark-field observation (Figure $7 b$ ) in addition to bright-field observation 
(Figure 7c), and Nomarski differential interference contrast (N-DIC) imaging as well. N-DIC imaging

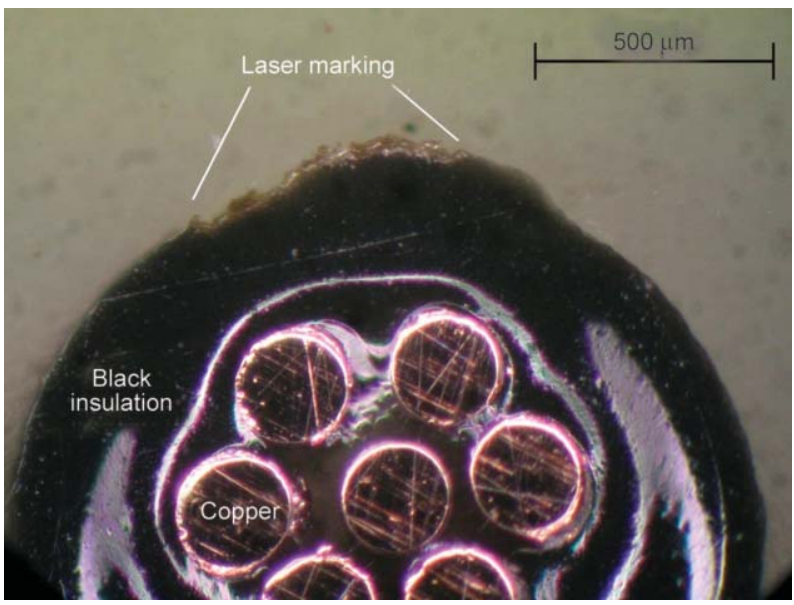

Figure 6. The cross-sectional image of the cables with black insulation; marking with the $1064 \mathrm{~nm}$ laser changed the surface into a light colour.

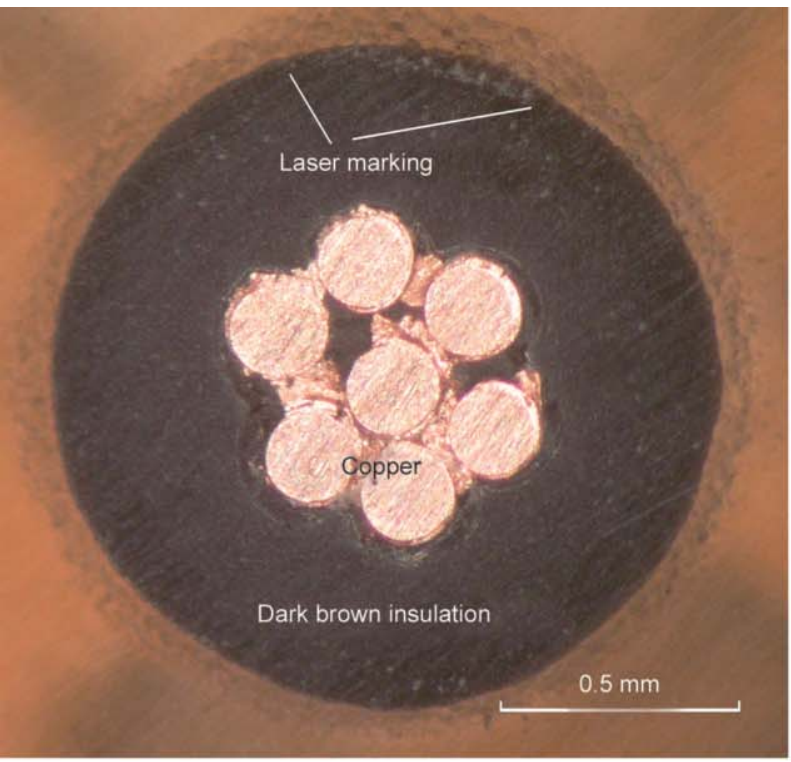

a)

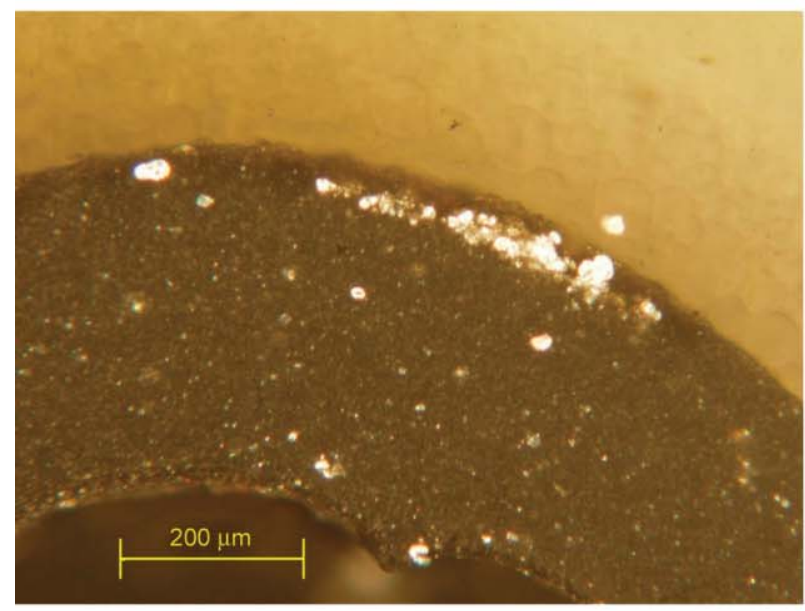

c) showed that the laser produced little pores inside the material (Figure 7d), that is, during marking, foaming also started in addition to whitening.

Table 3 shows the penetration depth of laser markings in Figure 2, as determined with the microscopic

Table 3. The penetration depth of markings in metric units and as a percentage of the thickness of the insulation.

\begin{tabular}{|l|c|c|c|}
\hline \multirow{2}{*}{$\begin{array}{c}\text { Colour of the } \\
\text { insulation }\end{array}$} & $\begin{array}{c}\text { Wavelength of the } \\
\text { laser beam } \\
{[\mathbf{n m}]}\end{array}$ & \multicolumn{2}{c|}{ Penetration depth } \\
\cline { 3 - 4 } & 532 & {$[\boldsymbol{\mu m}]$} & {$[\%]$} \\
\hline Yellow & 1064 & 45 & 39.0 \\
\hline (Green) Yellow & 1064 & 32 & 7.9 \\
\hline Green (Yellow) & 1064 & 88 & 21.2 \\
\hline Red & 1064 & $67(+50)$ & $23(40.3)$ \\
\hline Red-black & 1064 & 72 & 18.4 \\
\hline Black & 1064 & 66 & 15.7 \\
\hline Dark brown & & &
\end{tabular}

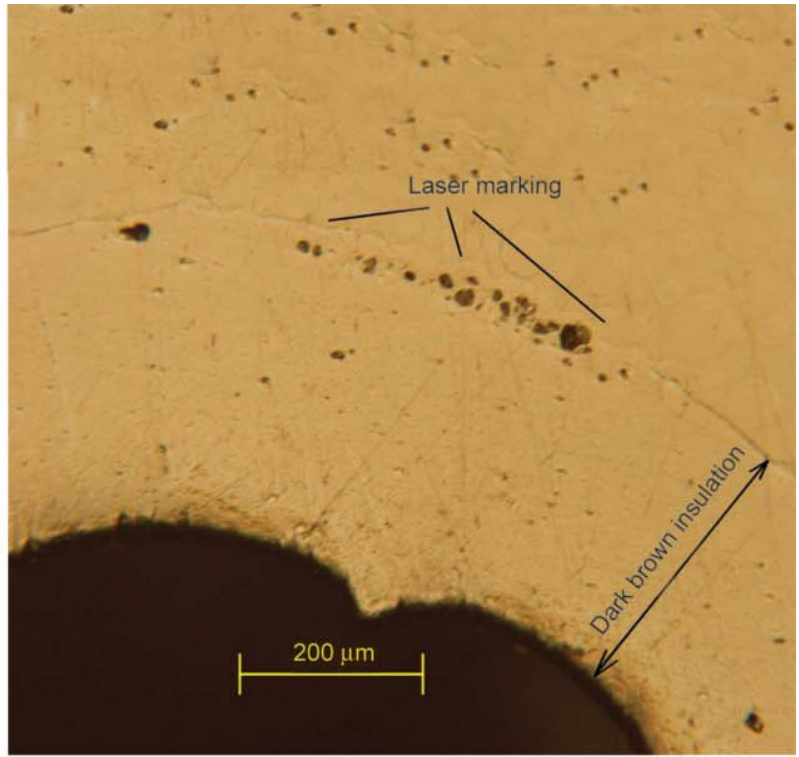

b)

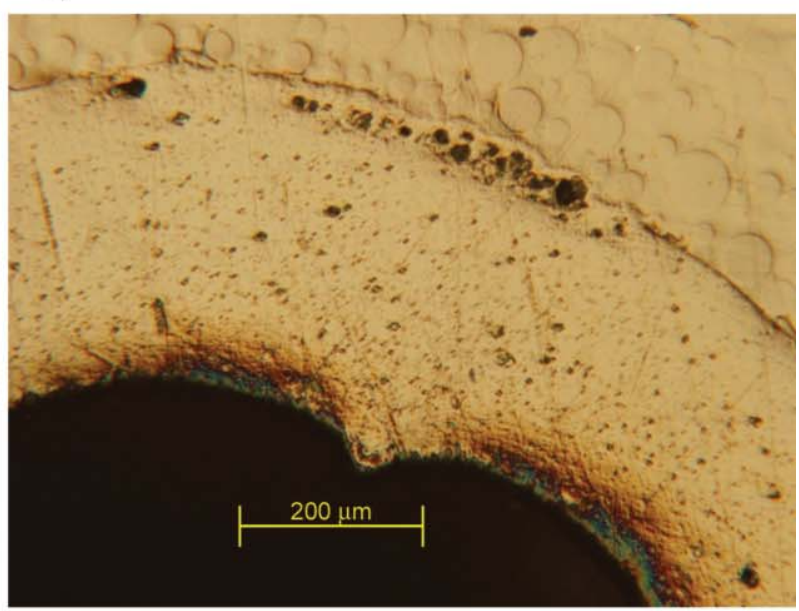

d)

Figure 7. The cross-sectional image of the laser marking of cables with dark brown insulation; a) stereo-microscopic image, b) dark-field image, c) bright-field image, d) N-DIC image. 
examination of the cross sections. Penetration depths are given in metric and relative units as well. Regarding the red-black insulation the $+50 \mu \mathrm{m}$ means the thickness of the transparent external coating. The data show that with the use of $1064 \mathrm{~nm}$ laser, penetration depth can be kept under 100 micrometers, while the visibility characteristics of marking are completely acceptable.

\section{Conclusions}

When using a laser beam of $1064 \mathrm{~nm}$ in 'marking on the fly' conditions, the marking has good contrast for all the different materials, except the yellow insulation. With fast speed, however, it can only produce good contrast on black, brown and green insulations. With slow speed, the $532 \mathrm{~nm}$ laser beam can mark all the materials with good contrast, but with fast speed it can hardly produce contrast with any of the materials. Of the insulations of various colours, the laser markability of the yellow insulation was found to be the most problematic.

The black and dark brown insulations also showed the first signs of foaming.

Not only the visual characteristics of laser markings - colour, contrast, homogeneity, scratch resistance but also their surface morphology can be controlled with the technological variables of laser marking; however, the material of the surface and the zone near the surface melts in every case and this leads to local degradation.

The penetration depth of laser marking depends considerably on the colour of the insulation of the cables. Compared to the generally accepted markability colour range, we found that $1064 \mathrm{~nm}$ laser beam penetrates into red PVC more deeply than into black and the penetration depth into green PVC is smaller than into the yellow. However, the results showed that the markability of yellow insulation is the most problematic.

When the insulation is covered with a transparent layer, the colour of marking is dark (black) in spite of the whitening of the red material. This is because the heat generated at the polymer phase boundary heats the transparent layer and turns it into black. In the case of such coextruded insulations, the separation of the layers is expected.

It is not difficult to stay within the technological range of colour change (thermal bleaching) marking with the $1064 \mathrm{~nm}$ laser in the case of PVC, but in the case of black and dark brown, the first signs of foaming can appear, which is not always acceptable.

\section{Acknowledgements}

Enikő Bitay was supported in her research project by the MTA

Domus Hungarica Grant Program: 5634/5/2017/ HTMT

\section{References}

[1] Wang H., Lan W-G., Lin W-Z., Mo D.: Relaxation dynamics of photoinduced exciton bleaching in polymers. Acta Physica Sinica (Overseas Edition), 5, 662-669 (1996). https://doi.org/10.1088/1004-423X/5/9/004

[2] Sazanov Y. N., Gribanov A. V.: Criteria of polymer carbonization. Russian Journal of Applied Chemistry, 82, 473-482 (2009). https://doi.org/10.1134/S1070427209030239

[3] McKee T. J., Toth L., Sauerer W.: Customized decorating of plastic parts with gray scale and multi-color images using lasers. in 'Coloring technology for plastics' (ed.: Harris R. M.) William Andrew, Norwich, 295-300 (1999).

https://doi.org/10.1016/B978-188420778-5.50038-3

[4] Burgess A., Feng K.: Color laser marking: A new marking and decorating alternative for olefins. in 'Coloring technology for plastics' (ed.: Harris R. M.) William Andrew, Norwich, 301-307 (1999).

https://doi.org/10.1016/B978-188420778-5.50039-5

[5] Zheng H., Lim G. C.: Laser-effected darkening in TPEs with $\mathrm{TiO}_{2}$ additives. Optics and Lasers in Engineering, 41, 791-800 (2004)

https://doi.org/10.1016/S0143-8166(03)00032-0

[6] Berman M. R.: Excimer laser darkening of ETFE polymer films. Journal of Applied Polymer Science, 45, 111-117 (1992). https://doi.org/10.1002/app.1992.070450113

[7] Lawrence B. D., Wharram S., Kluge J. A., Leisk G. G., Omenetto F. G., Rosenblatt M. I., Kaplan D. L.: Effect of hydration on silk film material properties. Macromolecular Bioscience, 10, 393-403 (2010). https://doi.org/10.1002/mabi.200900294

[8] Savu I. D., Savu S. V., Sirbu N. A.: Heat affected zones in polymer laser marking. Journal of Thermal Analysis and Calorimetry, 115, 1427-1437 (2014). https://doi.org/10.1007/s10973-013-3443-2

[9] Krüger J., Martin S., Mädebach H., Urech L., Lippert T., Wokaun A., Kautek W.: Femto- and nanosecond laser treatment of doped polymethylmethacrylate. Applied Surface Science, 247, 406-411 (2005). https://doi.org/10.1016/j.apsusc.2005.01.078

[10] Angelova Y., Mežinska S., Lazov L.: Innovative laser technology in textile industry: Marking and engraving. Environment. Technology. Resources, 3, 15-21 (2017). https://doi.org/10.17770/etr2017vol3.2610 
[11] Lazov L., Deneva H., Narica P.: Laser marking methods. Environment. Technology. Resources, 1, 108-115 (2015).

https://doi.org/10.17770/etr2015vol1.221

[12] Käpylä E., Aydogan D. B., Virjula S., Vanhatupa S., Miettinen S., Hyttinen J., Kellomäki M.: Direct laser writing and geometrical analysis of scaffolds with designed pore architecture for three-dimensional cell culturing. Journal of Micromechanics and Microengineering, 22, 115016/1-115016/13 (2012).

https://doi.org/10.1088/0960-1317/22/11/115016

[13] Lavieja C., Clemente M. J., Oriol L., Peña J. I.: Influence of the wavelength on laser marking on ABS filled with carbon black. Polymer-Plastics Technology and Engineering, 56, 1599-1607 (2017).

https://doi.org/10.1080/03602559.2017.1280735

[14] Breuer J., Metev S., Sepold F.: Photolytic surface modification of polymers with UV-laser radiation. Journal of Adhesion Science and Technology, 9, 351-363 (1995). https://doi.org/10.1163/156856195X00545

[15] Li X., He W., Lei L., Guo G., Zhang T., Yue T., Huang L.: Controlled laser-induced oxidation marking for submillimeter unique identification tags based on X-ray fluorescence. IEEE Photonics Journal, 8, 2400314/12400314/15 (2016).

https://doi.org/10.1109/JPHOT.2016.2531584

[16] Bosman J.: Processes and strategies for solid state Qswitch laser marking of polymers. $\mathrm{PhD}$ thesis, University of Twente (2007).

[17] Blanchet G. B.: Laser ablation and the unzipping of addition polymer. Journal of Applied Physics, 80, 4082 4089 (1996).

https://doi.org/10.1063/1.363278

[18] Shin Y., Kim Y., Park S., Jung B., Lee J., Nelson J. S.: Pit and rim formation during laser marking of acrylonitrile butadiene styrene plastic. Journal of Laser Applications, 17, 243-246 (2005).

https://doi.org/10.2351/1.2080405

[19] Reif J., Costache F., Henyk M., Pandelov S. V.: Ripples revisited: Non-classical morphology at the bottom of femtosecond laser ablation craters in transparent dielectrics. Applied Surface Science, 197-198, 891-895 (2002).

https://doi.org/10.1016/S0169-4332(02)00450-6

[20] Feng Y., Liu Z. Q., Yi X-S.: Marking carbon black/polypropylene compounds using a Nd:YAG laser. Journal of Materials Science Letters, 20, 517-519 (2001). https://doi.org/10.1023/A:1010968214597

[21] Yi X-S., Feng Y.: Etching behavior of plastics using a near infrared laser. Journal of Materials Science Letters, 18, 245-247 (1999). https://doi.org/10.1023/A:1006690029986

[22] Reyna L., Soběhart J. R.: Laser ablation of multilayer polymer films. Journal of Applied Physics, 76, 4367 4371 (1994).

https://doi.org/10.1063/1.357325
[23] Reyna L., Soběhart J. R.: Repetition rate effect on the laser ablation of polymer structures. Journal of Applied Physics, 78, 3423-3427 (1996).

https://doi.org/10.1063/1.359971

[24] Yeh J. T. C.: Laser ablation of polymers. Journal of Vacuum Science and Technology A, 4, 653-658 (1986). https://doi.org/10.1116/1.573823

[25] Arnold N., Bityurin N.: Model for laser-induced thermal degradation and ablation of polymers. Applied Physics A, 68, 615-625 (1999). https://doi.org/10.1007/s003390050950

[26] Bityurin N., Luk'yanchuk B. S., Hong M. H., Chong T. C.: Models for laser ablation of polymers. Chemical Reviews, 103, 519-552 (2003). https://doi.org/10.1021/cr010426b

[27] Martinez D., Dicara C. I., Hanus F., Kolev K., Laude L. D.: L'ablation des polymères par irradiation laser excimère: Le processus physique et la structure du polymère (in French). Journal de Physique IV France, 11, Pr7/107-Pr7/110 (2001). https://doi.org/10.1051/jp4:2001734

[28] Sohn I-B., Noh Y-C., Choi S-C., Ko D-K., Lee J., Choi Y-J.: Femtosecond laser ablation of polypropylene for breathable film. Applied Surface Science, 254, 49194924 (2008).

https://doi.org/10.1016/j.apsusc.2008.01.166

[29] Lippert T., Yabe A., Wokaun A.: Laser ablation of doped polymer systems. Advanced Materials, 9, 105119 (1997).

https://doi.org/10.1002/adma.19970090203

[30] Belaud V., Valette S., Stremsdoerfer G., Beaugiraud B., Audouard E., Benayoun S.: Femtosecond laser ablation of polypropylene: A statistical approach of morphological data. Scanning, 36, 209-217 (2014).

https://doi.org/10.1002/sca.21090

[31] Pazokian H., Selimis A., Barzin J., Jelvani S., Mollabashi M., Fotakis C., Stratakis E.: Tailoring the wetting properties of polymers from highly hydrophilic to superhydrophobic using UV laser pulses. Journal of Micromechanics and Microengineering, 22, 035001/1035001/7 (2012).

https://oi.org/10.1088/0960-1317/22/3/035001

[32] Bico J., Thiele U., Quéré D.: Wetting of textured surfaces. Colloids and Surfaces A: Physicochemical and Engineering Aspects, 206, 41-46 (2002). https://doi.org/10.1016/S0927-7757(02)00061-4

[33] Bremus-Koebberling E., Meier-Mahlo U., Henkenjohann O., Beckemper S., Gillner A.: Laser structuring and modification of polymer surfaces for chemical and medical microcomponents. in 'Proceedings of SPIE 2004, Nara, Japan’ Vol. 5662, p6 (2004).

https://doi.org/10.1117/12.596329

[34] Rebollar E., Vázquez de Aldana J. R., Pérez-Hernández J. A., Ezquerra T. A., Moreno P., Castillejo M.: Ultraviolet and infrared femtosecond laser induced periodic surface structures on thin polymer films. Applied Physics Letters, 100, 041106/1-041106/4 (2012). https://doi.org/10.1063/1.3679103 
[35] Saarikoski I., Suvanto M., Pakkanen T. A.: Modification of polycarbonate surface properties by nano-, micro, and hierarchical micro-nanostructuring. Applied Surface Science, 255, 9000-9005 (2009). https://doi.org/10.1016/j.apsusc.2009.06.073

[36] Costache F., Henyk M., Reif J.: Surface patterning on insulators upon femtosecond laser ablation. Applied Surface Science, 208-209, 486-491 (2003). https://doi.org/10.1016/S0169-4332(02)01443-5

[37] Guo C., Feng L., Zhai J., Wang G., Song Y., Jiang L., Zhu D.: Large-area fabrication of a nanostructure-induced hydrophobic surface from a hydrophilic polymer. ChemPhysChem, 5, 750-753 (2004). https://doi.org/10.1002/cphc.200400013

[38] Bartolo D., Bouamrirene F., Verneuil E., Buguin A., Silberzan P., Moulinet S.: Bouncing or sticky droplets: Impalement transitions on superhydrophobic micropatterned surfaces. Europhysics Letters, 74, 299-305 (2006). https://doi.org/10.1209/epl/i2005-10522-3

[39] Wang Z. K., Zheng H. Y., Lim C. P., Lam Y. C.: Polymer hydrophilicity and hydrophobicity induced by femtosecond laser direct irradiation. Applied Physics Letters, 95, 111110/1-111110/3 (2009). https://doi.org/10.1063/1.3232212

[40] Li W., Bakhtiary Noodeh M., Delpouve N., Saiter J-M., Tan L., Negahban M.: Printing continuously graded interpenetrating polymer networks of acrylate/epoxy by manipulating cationic network formation during stereolithography. Express Polymer Letters, 10, 1003-1015 (2016).

https://doi.org/10.3144/expresspolymlett.2016.93

[41] Malinauskas M., Žukauskas A., Hasegawa S., Hayasaki Y., Mizeikis V., Buividas R., Juodkazis S.: Ultrafast laser processing of materials: From science to industry. Light: Science and Applications, 5, 1-14 (2016) https://doi.org/10.1038/1sa.2016.133

[42] EN 2346-005: Aerospace series. Cable, electrical, fire resistant. Operating temperatures between $65^{\circ} \mathrm{C}$ and $260^{\circ} \mathrm{C}$. Part 005: DW family, single UV laser printable and multicore assembly. Light weight. Product standard (2014).

[43] EN 4650:2010: Aerospace series - Wire and cable marking process, UV Laser (2010).

[44] EN 3475-706: Aerospace series. Cables, electrical, aircraft use. Test methods. Part 706: Laser markability (2006).

[45] EN 3838 Aerospace series - Requirements and tests on user-applied markings on aircraft electrical cables (2010).

[46] Otuka A. J. G., Almeida J. M. P., Tribuzi V., Cardoso M. R., Hernandes A. C., Correa D. S., Mendonça C. R.: Femtosecond lasers for processing glassy and polymeric materials. Materials Research, 17, 352-358 (2014). https://doi.org/10.1590/S1516-14392013005000158
[47] Dass S. C.: Interaction of lasers with plastics and other materials. in 'Coloring technology for plastics' (ed.: Harris R. M.) William Andrew, Norwich, 289-294 (1999). https://doi.org/10.1016/B978-188420778-5.50037-1

[48] Potente H., Korte J., Becker F.: Laser transmission welding of thermoplastics: Analysis of the heating phase. in 'Coloring technology for plastics' (ed.: Harris R. M.) William Andrew, Norwich, 283-288 (1999). https://doi.org/10.1016/B978-188420778-5.50036-X

[49] Baudach S., Bonse J., Kautek W.: Ablation experiments on polyimide with femtosecond laser pulses. Applied Physics A, 69, S395-S398 (1999).

https://doi.org/10.1007/s003390051424

[50] Baudach S., Bonse J., Krüger J., Kautek W.: Ultrashort pulse laser ablation of polycarbonate and polymethylmethacrylate. Applied Surface Science, 154-155, 555$560(2000)$.

https://doi.org/10.1016/S0169-4332(99)00474-2

[51] Costache F., Henyk M., Reif J.: Modification of dielectric surfaces with ultra-short laser pulses. Applied Surface Science, 186, 352-357 (2002). https://doi.org/10.1016/S0169-4332(01)00675-4

[52] Zhong W., Cao Z., Qiu P., Wu D., Liu C., Li H., Zhu H.: Laser-marking mechanism of thermoplastic polyurethane $/ \mathrm{Bi}_{2} \mathrm{O}_{3}$ composites. ACS Applied Materials Interfaces, 7, 24142-24149 (2015). https://doi.org/10.1021/acsami.5b07406

[53] Glaser S.: Colorants and special additives for laser welding. in 'International Conference on Joining Plastics, London, UK' 23/1-23/5 (2006).

[54] Wissemborski R., Klein R.: Welding and marking of plastics with lasers. Laser Technik Journal, 7, 19-22 (2010). https://doi.org/10.1002/latj.201090070

[55] Babich J. D., Edler G.: The enhancement of laser marking plastic polymers with pearlescent pigments. in 'Coloring technology for plastics' (ed.: Harris R. M.) William Andrew, Norwich, 323-326 (1999). https://doi.org/10.1016/B978-188420778-5.50042-5

[56] White J.: Complex inorganic color pigments: An overview. in 'High performance pigments' (ed: Smith H. M.) Wiley, Weinheim, 41-51 (2003). https://doi.org/10.1002/3527600493.ch5

[57] Perez Graterol R. M., Van Duijnhoven F. G. H., Gelissen F. W. M., Hoekstra J.: Laser-markable polyamide composition. U.S. Patent 15311346, USA (2017).

[58] Legentil B.: Compositions for coloured marking of plastic materials by laser irradiation. EP0684144B1, EU (1998).

[59] Williams S. W.: A laser markable white pigment composition. EP0447032A2, EU (1991).

[60] Bormashenko E., Pogreb R., Sheshnev A., Shulzinger E., Bormashenko Y., Katzir A.: IR laser radiation induced changes in the IR absorption spectra of thermoplastic and thermosetting polymers. Journal of Optics A: Pure and Applied Optics, 3, 229-232 (2001) https://doi.org/10.1088/1464-4258/3/4/301 
[61] Shukla S. R., Kapadi P. U., Mhaske S. T., Mali M. N., More A.: Synthesis of a secondary plasticizer for poly (vinyl chloride) by recycling of poly(ethylene terephthalate) bottle waste through aminolytic depolymerization. Journal of Vinyl and Additive Technology, 23, 152-160 (2017).

https://doi.org/10.1002/vnl.21494

[62] Linde E., Gedde U. W.: Plasticizer migration from PVC cable insulation - The challenges of extrapolation methods. Polymer Degradation and Stability, 101, 24-31 (2014).

https://doi.org/10.1016/j.polymdegradstab.2014.01.021

[63] Greco A., Ferrari F., Del Sole R., Maffezzoli A.: Use of cardanol derivatives as plasticizers for PVC. Journal of Vinyl and Additive Technology, 24, E62-E70 (2018). https://doi.org/10.1002/vnl.21585

[64] Bitinis N., Verdejo R., Cassagnau P., Lopez-Manchado M. A.: Structure and properties of polylactide/natural rubber blends. Materials Chemistry and Physics, 129, 823-831 (2011).

https://doi.org/10.1016/j.matchemphys.2011.05.016

[65] Cruz-Estrada R. H., Martínez-Tapia E., Canché-Escamilla G., González-Chí P. I., Martiın-Barrera C., Duarte-Aranda S., Guillén-Mallette J., Cupul-Manzano C. V., Martínez Dominguez O., García-Gómez C.: A preliminary study on the preparation of wood-plastic composites from urban wastes generated in Merida, Mexico with potential applications as building materials. Waste Management and Research, 28, 838-847 (2010). https://doi.org/10.1177/0734242X09350059

[66] Luckachan G. E., Pillai C.: Biodegradable polymers A review on recent trends and emerging perspectives. Journal of Polymers and the Environment, 19, 637-676 (2011).

https://doi.org/10.1007/s10924-011-0317-1

[67] Flaris V., Singh G.: Recent developments in biopolymers. Journal of Vinyl and Additive Technology, 15, 111 (2009). https://doi.org/10.1002/vnl.20171

[68] Bueno-Ferrer C., Garrigós M. C., Jiménez A.: Characterization and thermal stability of poly(vinyl chloride) plasticized with epoxidized soybean oil for food packaging. Polymer Degradation and Stability, 95, $2207-$ 2212 (2010).

https://doi.org/10.1016/j.polymdegradstab.2010.01.027
[69] Sun B., Chaudhary B. I., Shen C-Y., Mao D., Yuan D-M., Dai G-C., Li B., Cogen J. M.: Thermal stability of epoxidized soybean oil and its absorption and migration in poly(vinyl chloride). Polymer Engineering and Science, 53, 1645-1656 (2013). https://doi.org/10.1002/pen.23417

[70] Ionescu M., Wan X., Bilić N., Petrović Z. S.: Polyols and rigid polyurethane foams from cashew nut shell liquid. Journal of Polymers and the Environment, 20, 647658 (2012).

https://doi.org/10.1007/s10924-012-0467-9

[71] Sakulsaknimitr W., Wirasate S., Pipatpanyanugoon K., Atorngitjawat N.: Structure and thermal properties of polyurethanes synthesized from cardanol diol. Journal of Polymers and the Environment, 23, 216-226 (2015). https://doi.org/10.1007/s10924-014-0707-2

[72] Besteti M. D., Souza F. G. Freire Jr, D. M. G., Pinto J. C.: Production of core-shell polymer particles-containing cardanol by semibatch combined suspension/emulsion polymerization. Polymer Engineering and Science, 54, 1222-1229 (2014). https://doi.org/10.1002/pen.23660

[73] Calò E., Greco A., Maffezzoli A.: Effects of diffusion of a naturally-derived plasticizer from soft PVC. Polymer Degradation and Stability, 96, 784-789 (2011). https://doi.org/10.1016/j.polymdegradstab.2011.02.012

[74] Li X., Nie X., Chen J., Wang Y.: Preparation of epoxidized cardanol butyl ether as a novel renewable plasticizer and its application for poly(vinyl chloride). Polymer International, 66, 443-449 (2017).

https://doi.org/10.1002/pi.5280

[75] Zheng H. Y., Rosseinsky D., Lim G. C.: Laser-evoked coloration in polymers. Applied Surface Science, 245, 191-195 (2005). https://doi.org/10.1016/j.apsusc.2004.10.008

[76] Zelenska K. S., Zelensky S. E., Poperenko L. V., Kanev K., Mizeikis V., Gnatyuk V. A.: Thermal mechanisms of laser marking in transparent polymers with light-absorbing microparticles. Optics and Laser Technology, 76, 96-100 (2016). https://doi.org/10.1016/j.optlastec.2015.07.011 